\title{
Phenolic compounds profile, nutritional compounds and bioactive properties of Lycium barbarum L.: A comparative study with stems and fruits
}

\author{
Tânia C.S.P. Pires ${ }^{\mathrm{a}, \mathrm{b}}$, Maria Inês Dias ${ }^{\mathrm{a}}$, Lillian Barros ${ }^{\mathrm{a}, *}$, Ricardo C. Calhelha ${ }^{\mathrm{a}}$, Maria José Alves ${ }^{\mathrm{a}}$, \\ Celestino Santos-Buelga ${ }^{\mathrm{b}}$, Isabel C.F.R. Ferreira ${ }^{\mathrm{a}, *}$
}

${ }^{a}$ Centro de Investigação de Montanha (CIMO), Instituto Politécnico de Bragança, Campus de Santa Apolónia, 5300-253 Bragança, Portugal

${ }^{\mathrm{b}}$ Grupo de Investigación en Polifenoles (GIP-USAL), Facultad de Farmacia, Universidad de Salamanca, Campus Miguel de Unamuno s/n, 37007 Salamanca, Spain

\section{A R T I C L E I N F O}

\section{Keywords:}

Lycium barbarum L.

Fruits/stems

Nutritional value

Phenolic composition

Bioactive properties

\begin{abstract}
A B S T R A C T
The increasing awareness of the possible health benefits of berry fruits (Lycium barbarum L.) has led to a higher consumption of this type of food products. One of the many examples are the fruits from Lycium genus, traditionally used due to their beneficial properties and health benefits associated with liver, kidney, eyesight, immune system, circulation and longevity disorders. In the present study fruits and stems of Lycium barbarum L. (goji) were characterized in terms of nutritional profile, sugars, organic acids, fatty acids and tocopherols. Furthermore, a phenolic characterization of their hydromethanolic extracts was performed and correlated with bioactive properties such as antioxidant, hepatotoxic and antibacterial activities. Stems presented higher values of energy, MUFA (monounsaturated fatty acids), tocopherols and flavonols. Stems also showed greater antioxidant and antibacterial (against Gram-negative bacteria) activities. Otherwise, fruits revealed higher contents of sugars, PUFA (polyunsaturated fatty acids) and hydroxycinnamic acid derivatives, and greater activity against Gram-positive bacteria. This is an innovative study that shows the high potential of goji stems and fruits as sources of bioactive compounds, which could be used in nutraceutical formulations, or incorporated into food products with functional properties. Furthermore, the use of stems could bring industrial sustainability as a valuable by-product, which has been scarcely reported.
\end{abstract}

\section{Introduction}

The interest in many traditional herbs and plant food supplements, as a source of nutritional antioxidants, is due to the increasing knowledge of the role of antioxidants and free radicals in human health (Dahech et al., 2013). The consumption of plants belonging to the Lycium genus has increased exponentially, not only due to their traditionally usage in Chinese medicine, but also because of their wide acceptance as food ingredients (Dahech et al., 2013; Dong et al., 2009). The berries are commonly consumed in soups, as porridge with rice and added to numerous meat and vegetable dishes (Potterat and Food, 2010), eaten raw, as a juice, wine or in tea preparations, as also processed as tinctures, powders, and tablets (Potterat and Food, 2010).

One of the most widely studied species of this genus is Lycium barbarum L., which has several vernacular names, being "goji" the most common one (Amagase and Farnsworth, 2011). Since the beginning of the 21th century, goji products have been introduced in Europe and North America and their consumption has increased rapidly due to their claimed beneficial properties for wellbeing and longevity (D'Amato et al., 2013). Goji berries have been associated with a wide range of health benefits, including the treatment of diseases related to liver, kidney, eyesight, immune system, circulation and longevity, as also with sexual activity (Tang et al., 2012). Recent studies also suggest that L. barbarum leaves have shown a broad development and application prospects in the food industry due to the rich nutrients, biological active ingredients and trace elements (Liu et al., 2012).

The interest in the composition of berry fruits has been also intensified because of an increased awareness of their possible health benefits, as they are rich sources of micronutrients and phytochemicals such as polyphenols. Some of these phenolic compounds, which can act as antioxidants and antimicrobials, have been identified by different authors (Amagase and Farnsworth, 2011; Dahech et al., 2013; Liu et al., 2017), but to the authors' best knowledge there is no previous information about the chemical and bioactive characteristics of $L$. barbarum stems. The present study describes and compares the nutritional and chemical composition of Lycium barbarum L. stems and fruits; moreover, a phenolic characterization of its hydromethanolic extracts was performed and correlated with bioactive properties (e.g.,

\footnotetext{
* Corresponding authors.

E-mail addresses: lillian@ipb.pt (L. Barros), iferreira@ipb.pt (I.C.F.R. Ferreira).
} 
antioxidant, hepatotoxic and antimicrobial). The results of this study might be useful to maximize the potential of stems as by-products with functional properties with interest in food and pharmaceutical industries.

\section{Materials and methods}

\subsection{Standards and reagents}

Acetonitrile (99.9\%) was of HPLC grade from Fisher Scientific (Lisbon, Portugal). Phenolic standards were from Extrasynthèse (Genay, France). Sulforhodamine B, trypan blue, trichloroacetic acid (TCA), tris (hydroxymethyl)aminomethane (Tris), Trolox (6-hydroxy-2,5,7,8-tetramethylchroman-2-carboxylic acid) and formic acid were purchased from Sigma-Aldrich (St. Louis, MO, USA). 2,2-Diphenyl-1-picrylhydrazyl (DPPH) was obtained from Alfa Aesar (Ward Hill, MA, USA). $p$ Iodonitrotetrazolium chloride (INT) was from Panreac Applichem (Barcelona, Spain), Tryptic Soy Broth (TSB) and Mueller-Hinton (MH) were purchased from Biolab ${ }^{\circledR}$ (Hungary). All other general laboratorial reagents were from Panreac Química S.L.U. (Barcelona, Spain). Water was treated in a Milli-Q water purification system (TGI Pure Water Systems, USA).

\subsection{Samples}

The dried fruits and stems of Lycium barbarum L. were supplied by the company RBR foods from Castro Daire (Portugal). After reception, the dried fruits and stems were reduced to a fine dried powder $(\sim 20$ mesh) and mixed to obtain homogenate samples.

\subsection{Nutritional value of L. barbarum fruits and stems}

\subsubsection{Proximate composition and energetic value}

The dehydrated and powdered fruits and stems were analysed for proteins, fat, carbohydrates and ash according to the AOAC (Association of Official Analytical Chemists) procedures (AOAC, 2016). The AOAC 991.02 was followed to determine the crude protein content ( $\times$ 6.25, macro-Kjeldahl method); AOAC 989.05 was used to determine crude fat (Soxhlet apparatus with petroleum ether as extraction solvent); AOAC 935.42 was used for ash content determination (incineration at $550 \pm 15^{\circ} \mathrm{C}$ ). The total carbohydrates (including fiber) were calculated by difference, according with the equation: Total carbohydrates $(\mathrm{g} / 100 \mathrm{~g})=100-(\mathrm{g}$ fat $+\mathrm{g}$ protein $+\mathrm{g}$ ash $)$. Total energy was calculated according to the following equation: Energy (kcal/ $100 \mathrm{~g})=4 \times(\mathrm{g}$ proteins $+\mathrm{g}$ carbohydrates $)+9 \times(\mathrm{g}$ fat $)$.

\subsubsection{Fatty acids}

Fatty acids were determined by using a Soxhlet extraction of the dehydrated and powdered fruits and stems in order to obtain a lipidic fraction and after a trans-esterification process, being further analysed by gas chromatography coupled with a flame ionization detector (GCFID; DANI model GC 1000 instrument, Contone, Switzerland), according to the procedure previously described by the authors (Dias et al., 2015). The results were expressed in relative percentage of each fatty acid.

\subsubsection{Soluble sugars}

Soluble sugars were determined in the dehydrated and powdered fruits and stems following a procedure previously described by the authors (Dias et al., 2015). A High performance liquid chromatography system coupled to a refraction index detector (HPLC-RI; Knauer, Smartline system 1000, Berlin, Germany) was used to identify and quantify the soluble sugars. The quantification was performed using the internal standard (melezitose) and the results were expressed in $g$ per $100 \mathrm{~g}$ of fruits and stems dry weight.

\subsubsection{Organic acids}

The dehydrated and powdered fruits and stems were analysed for its organic acids following the procedure previously described by the authors (Dias et al., 2015), using an ultra-fast liquid chromatography coupled to photodiode array detector (UFLC-PDA; Shimadzu Coperation, Kyoto, Japan). The quantification was performed by comparison of the peak area recorded at $215 \mathrm{~nm}$ as preferred wavelength. For quantitative analysis, a calibration curve with known concentration $(10-0.0078 \mathrm{mg} / \mathrm{mL})$ for each available organic acid, was constructed based on the UV signal: oxalic acid (y $=45,973+9 \times 10^{6} x$, $\left.R^{2}=0.9901\right) ;$ quinic acid $\left(\mathrm{y}=46,061+610607 x, R^{2}=0.9995\right)$; malic acid $\left(\mathrm{y}=92,665+912441 x, \quad R^{2}=0.999\right) ; \quad$ citric acid (y $\left.=45,682+1 \times 10^{6} x, \quad R^{2}=0.9997\right), \quad$ and succinic acid $\left(y=50,689+592888 x, R^{2}=0.9996\right)$. The results were expressed in $g$ per $100 \mathrm{~g}$ of fruits and stems dry weight.

\subsubsection{Tocopherols}

Tocopherols (four vitamers) were determined according with the procedure previously described by the authors (Dias et al., 2015), in the dehydrated and powdered fruits and stems, by HPLC (Knauer, Smartline system 1000, Berlin, Germany) coupled to a fluorescence detector (FP-2020; Jasco, Easton, MD, USA). For the quantification, an internal standard (tocol) was used, based on the fluorescence signal response of each standard. The results were expressed in $\mathrm{mg}$ per $100 \mathrm{~g}$ of fruits and stems dry weight.

\subsection{Analysis of phenolic compounds}

\subsubsection{Preparation of the hydromethanolic extracts}

To prepare the hydromethanolic extracts, $1 \mathrm{~g}$ of each dehydrated and powdered sample was extracted with a methanol/water mixture (80:20, $v / v)$, at $25^{\circ} \mathrm{C}$ and $150 \mathrm{rpm}$, during $1 \mathrm{~h}$, followed by filtration through a Whatman filter paper No. 4 . The remaining residue was reextracted with one additional portion of the methanol/water mixture, and the combined extracts were evaporated under reduced pressure (rotary evaporator Büchi R-210, Flawil, Switzerland) to remove the methanol; then the extracts were frozen, lyophilized and stored at $-5{ }^{\circ} \mathrm{C}$ for further analysis.

\subsubsection{Phenolic compounds}

The hydromethanolic extracts were re-dissolved at a concentration of $5 \mathrm{mg} / \mathrm{mL}$ in methanol/water $(80: 20, \mathrm{v} / \mathrm{v})$. The analysis was performed using a LC-DAD-ESI/MSn (Dionex Ultimate 3000 UPLC, Thermo Scientific, San Jose, CA, USA) as previously described by (Bessada et al., 2016). The detection was performed using 280,330 and $370 \mathrm{~nm}$ as preferred wavelengths for DAD and in a mass spectrometer equipped with an ESI source and performed in negative mode (Linear Ion Trap LTQ XL mass spectrometer, Thermo Finnigan, San Jose, CA, USA). The identification of the phenolic compounds was performed based on its chromatographic behaviour and UV-vis and mass spectra by comparison with available standard compounds, and data reported in the literature giving a tentative identification. For quantitative analysis, a calibration curve with known concentration $(200-5 \mu \mathrm{g} / \mathrm{mL})$ for each available phenolic standard: caffeic acid $(y=406,369+388345 x$, $\left.R^{2}=0.9949\right) ; \quad$ catequin $\left(y=-23,200+84950 x, \quad R^{2}=0.9999\right)$; chlorogenic acid $\left(y=-161,172+168823 x, R^{2}=0.9999\right)$; ferulic acid $\left(y=-185,462+633126 x, R^{2}=0.9999\right)$; kaempferol-3-O-rutinoside $\quad\left(y=30,861+11117 x ; \quad R^{2}=0.9998\right) ; \quad p$-coumaric acid $\left(y=6966.7+301950 x, \quad R^{2}=0.9999\right) ; \quad$ quercetin-3-O-rutinoside $\left(y=76,751+13343 x, \quad R^{2}=0.9998\right) ; \quad$ quercetin-3-O-glucoside $\left(y=-160,173+34843 x, \quad R^{2}=0.9998\right) ; \quad$ sinapic $\quad$ acid $\left(y=30,036+197337 x, R^{2}=0.9997\right)$, was constructed based on the UV signal. For the identified phenolic compounds for which a commercial standard was not available, the quantification was carried out through the calibration curve of the most similar available standard. The results were expressed as mg per $\mathrm{g}$ of extract. 


\subsection{Evaluation of bioactive properties}

\subsubsection{Antioxidant activity}

The hydromethanolic extracts were re-dissolved in methanol:water (80:20, v/v) to obtain stock solutions of $2.5 \mathrm{mg} / \mathrm{mL}$, which were further diluted to obtain a range of concentrations $(2.5 \mathrm{mg} / \mathrm{mL}$ to $0.07 \mathrm{mg} / \mathrm{mL})$ for antioxidant activity evaluation by DPPH radical-scavenging, reducing power, inhibition of $\beta$-carotene bleaching, and TBARS inhibition assays (Barros et al., 2013). The final results were expressed as EC $_{50}$ values $(\mathrm{mg} / \mathrm{mL})$, which means sample concentration providing $50 \%$ of antioxidant activity or 0.5 of absorbance in the reducing power assay. Trolox was used as a positive control.

\subsubsection{Antibacterial activity}

The hydromethanolic extracts were re-dissolved in water in order to obtain stock solutions of $100 \mathrm{mg} / \mathrm{mL}$, and then submitted to further dilutions. The microorganisms used were clinical isolates from patients hospitalized in various departments of the Local Health Unit of Bragança and Hospital Center of Trás-os-Montes and Alto-Douro Vila Real, Northeast of Portugal. Seven Gram-negative bacteria (Escherichia coli, E. coli ESBL (extended spectrum of beta-lactamase), Klebsiella pneumoniae, K. pneumoniae ESBL, Morganella morganii, Pseudomonas aeruginosa and Acinetobacter baumannii, isolated from urine and expectoration) and five Gram-positive bacteria (MRSA- methicillin-resistant Staphylococcus aureus, MSSA- methicillin-susceptible Staphylococcus aureus, Staphylococcus aureus, Listeria monocytogenes and Enterococcus faecalis) were used to screen the antibacterial activity. Minimum inhibitory concentrations (MIC) were determined by the microdilution method and the rapid $p$-iodonitrotetrazolium chloride (INT) colorimetric assay was used by following the methodology proposed by Kuete et al. (2011a,b) with some modifications (Dias et al., 2016). The antibiotic susceptibility profile was obtained for all the tested bacteria (Table A1, Supplementary material). MIC was defined as the lowest concentration that inhibits the visible bacterial growth.

\subsubsection{Hepatotoxicity}

The hydromethanolic extracts were re-dissolved in water to obtain stock solutions of $4 \mathrm{mg} / \mathrm{mL}$, and then submitted to further dilutions. For hepatotoxicity evaluation, a porcine liver cells primary culture (PLP2) was prepared from a freshly harvested porcine liver obtained from a local slaughterhouse, according to a procedure established by the authors (Abreu et al., 2011). Ellipticine was used as positive control and the results were expressed in $\mathrm{GI}_{50}$ values, concentration that inhibited $50 \%$ of the net cell growth.

\subsubsection{Statistical analysis}

Three samples were used for each plant part and all the assays were carried out in triplicate. The results were expressed as mean values and standard deviation (SD), being analysed using a Student's $t$-test, with $\alpha=0.05$. Furthermore, a Pearson's correlation analysis between the bioactivities and the different groups of phenolic compounds (sum of phenolic acids, sum of flavan-3-ols, sum of flavonols and sum of phenolic compounds) was carried out, with a $95 \%$ confidence level. The analyses were carried out using IBM SPSS Statistics for Windows, Version 22.0. (IBM Corp., Armonk, New York, USA).

\section{Results and discussion}

\subsection{Nutrient composition}

Data on the proximate composition and energetic value of $L$. barbarum are shown in Table 1. Carbohydrates were the most abundant macronutrients in fruits and stems $(87$ and $78.1 \mathrm{~g} / 100 \mathrm{~g} \mathrm{dw}$, respectively). Stems presented the highest contents of ash, proteins and fat (9.9, 7.4, and $4.6 \mathrm{~g} / 100 \mathrm{~g} \mathrm{dw}$, respectively), while fruits presented proteins as the second major macronutrient $(5.3 \mathrm{~g} / 100 \mathrm{~g} \mathrm{dw})$, followed
Table 1

Proximate composition, soluble sugars and organic acids in fruits and stems of Lycium barbarum L. (mean $\pm \mathrm{SD}$ ).

\begin{tabular}{|c|c|c|c|}
\hline & Fruits & Stems & $\begin{array}{l}t \text {-Students test } \\
p \text {-value }\end{array}$ \\
\hline \multicolumn{4}{|c|}{ Nutritional value (g/100 g dw) } \\
\hline Fat & $4.1 \pm 0.3$ & $4.6 \pm 0.3$ & 0.040 \\
\hline Proteins & $5.3 \pm 0.2$ & $7.4 \pm 0.2$ & $<0.001$ \\
\hline Ash & $3.21 \pm 0.02$ & $9.9 \pm 0.1$ & $<0.001$ \\
\hline Total carbohydrates & $87 \pm 6$ & $78.1 \pm 0.4$ & $<0.001$ \\
\hline $\begin{array}{l}\text { Energy contribution (kcal/ } \\
\quad 100 \mathrm{~g} \mathrm{dw})\end{array}$ & $408 \pm 1$ & $383 \pm 2$ & $<0.001$ \\
\hline \multicolumn{4}{|l|}{ Soluble sugars $(\mathrm{g} / 100 \mathrm{~g} \mathrm{dw})$} \\
\hline Fructose & $12.7 \pm 0.4$ & $0.45 \pm 0.01$ & $<0.001$ \\
\hline Glucose & $14.4 \pm 0.4$ & $0.42 \pm 0.01$ & $<0.001$ \\
\hline Sucrose & $0.8 \pm 0.1$ & $0.21 \pm 0.02$ & $<0.001$ \\
\hline Sum & $27.9 \pm 0.9$ & $1.08 \pm 0.05$ & $<0.001$ \\
\hline \multicolumn{4}{|l|}{ Organic acids (g/100g dw) } \\
\hline Oxalic acid & $0.010 \pm 0.001$ & $0.65 \pm 0.001$ & $<0.001$ \\
\hline Quinic acid & nd & $0.53 \pm 0.03$ & - \\
\hline Malic acid & nd & $0.899 \pm 0.004$ & - \\
\hline Citric acid & $1.29 \pm 0.02$ & nd & - \\
\hline Succinic acid & $0.77 \pm 0.07$ & nd & - \\
\hline Sum & $2.07 \pm 0.01$ & $2.08 \pm 0.03$ & 0.677 \\
\hline
\end{tabular}

dw - dry weight basis; nd - not detected.

by fat and ash (4.1 and $3.21 \mathrm{~g} / 100 \mathrm{~g} \mathrm{dw}$, respectively). Yan et al. (2014) reported different results for goji fruits from China, describing a higher content of proteins and fat ( 12.1 and $6.89 \mathrm{~g} / 100 \mathrm{~g} \mathrm{dw}$, respectively) and a lower ash content $(0.95 \mathrm{~g} / 100 \mathrm{~g} \mathrm{dw})$. These differences might be explained by the cultivar and/or different edaphic conditions that can lead to variable nutritional contents.

Soluble sugars and organic acids of the studied fruits and stems are also presented in Table 1. Fructose, glucose and sucrose were the only forms of monosaccharides detected in fruits and stems, being glucose the most abundant one, followed by fructose and sucrose. As expected, fruits presented much higher content in soluble sugars $(27.9 \mathrm{~g} / 100 \mathrm{~g}$ $\mathrm{dw})$ than stems $(1.08 \mathrm{~g} / 100 \mathrm{~g} \mathrm{dw})$. These results are in agreement with those obtained by Mikulic-Petkovsek et al. (2012) in goji fruits from Slovenia, where glucose and fructose were also the prevailing sugars detected, although those authors reported a higher total sugars content.

Regarding organic acids (Table 1), fruits and stems presented very different profiles, however, no statistically significant differences were found in the sum of the organic acids between samples. Citric, succinic and oxalic (1.29, 0.77 , and $0.010 \mathrm{~g} / 100 \mathrm{~g} \mathrm{dw}$, respectively) acids were detected in the fruit; while malic, oxalic and quinic $(0.899,0.65$, and $0.53 \mathrm{~g} / 100 \mathrm{~g} \mathrm{dw}$, respectively) acids were found in the stems. Oxalic acid was the only organic acid common in both samples. Donno et al. (2015), in goji fruits from Italy, reported the presence of several organic acids, including malic, quinic and tartaric acids that were not detected in samples of this study. These differences might be due to the physical state of the samples and/or the extraction method, as Donno et al. (2015) analysed the organic acids in fresh or semi-fresh samples (stored at $4{ }^{\circ} \mathrm{C}$ for a few days) and using ethanol as extraction solvent.

Fatty acids were also determined in fruits and stems of goji fruits and the results are shown in Table 2. Sixteen fatty acids were identified in the fruits, being polyunsaturated fatty acids (PUFA) the predominant group, mainly due to the presence of linoleic acid (C18:2n6, 53.4\%), followed by oleic acid (C18:1n9, 16.5\%) and palmitic acid (C16:0, $12.77 \%$ ). Similar results were obtained by Yan et al. (2014) in goji fruits from China, that described linoleic acid (66.81\%) and oleic acid $(17.13 \%)$ as the major fatty acids. In stem samples, eighteen fatty acids were identified, being saturated fatty acids (SFA) predominant, especially palmitic (C16:0, 15.94\%) and lignoceric acids (C24:0, 15.3\%), followed by linolenic acid (C18:3n3, 14.8\%).

Regarding tocopherols (Table 2), both samples presented only two vitamers. The highest content of tocopherols $(3.59 \mathrm{mg} / 100 \mathrm{~g} \mathrm{dw})$ was 
Table 2

Fatty acids and tocopherols in fruits and stems of Lycium barbarum L. (mean $\pm \mathrm{SD})$.

\begin{tabular}{|c|c|c|c|}
\hline & Fruits & Stems & $t$-Students test $p$-value \\
\hline \multicolumn{4}{|c|}{ Fatty acids (relative percentage, \%) } \\
\hline C8:0 & $0.65 \pm 0.04$ & $0.60 \pm 0.04$ & 0.020 \\
\hline C10:0 & $0.10 \pm 0.01$ & $0.15 \pm 0.01$ & $<0.001$ \\
\hline $\mathrm{C} 12: 0$ & $0.19 \pm 0.02$ & $0.19 \pm 0.02$ & 0.442 \\
\hline C14:0 & $0.38 \pm 0.02$ & $1.7 \pm 0.1$ & $<0.001$ \\
\hline C14:1 & $0.37 \pm 0.03$ & $0.35 \pm 0.02$ & 0.015 \\
\hline C15:0 & $0.21 \pm 0.02$ & $0.29 \pm 0.01$ & $<0.001$ \\
\hline $\mathrm{C} 16: 0$ & $12.77 \pm 0.07$ & $15.94 \pm 0.08$ & $<0.001$ \\
\hline C16:1 & $0.29 \pm 0.02$ & nd & - \\
\hline $\mathrm{C} 17: 0$ & $0.48 \pm 0.05$ & $0.90 \pm 0.04$ & $<0.001$ \\
\hline C18:0 & $7.50 \pm 0.06$ & $9.1 \pm 0.2$ & $<0.001$ \\
\hline C18:1n9 & $16.5 \pm 0.5$ & $5.12 \pm 0.06$ & $<0.001$ \\
\hline $\mathrm{C} 18: 2 \mathrm{n} 6$ & $53.4 \pm 0.5$ & $9.7 \pm 0.2$ & $<0.001$ \\
\hline C18:3n3 & $1.68 \pm 0.02$ & $14.8 \pm 0.3$ & $<0.001$ \\
\hline C20:0 & $1.30 \pm 0.07$ & $12.84 \pm 0.01$ & $<0.001$ \\
\hline C20:2 & nd & $1.3 \pm 0.2$ & - \\
\hline $\mathrm{C} 20: 3 \mathrm{n} 3$ & $0.35 \pm 0.04$ & $0.73 \pm 0.04$ & 0.000 \\
\hline C22:0 & $2.75 \pm 0.08$ & $10.4 \pm 0.1$ & $<0.001$ \\
\hline C23:0 & nd & $0.69 \pm 0.01$ & - \\
\hline $\mathrm{C} 24: 0$ & nd & $15.3 \pm 0.3$ & - \\
\hline SFA & $26.1 \pm 0.1$ & $68.0 \pm 0.5$ & $<0.001$ \\
\hline MUFA & $17.2 \pm 0.6$ & $5.46 \pm 0.04$ & $<0.001$ \\
\hline PUFA & $56.8 \pm 0.5$ & $26.6 \pm 0.4$ & $<0.001$ \\
\hline \multicolumn{4}{|c|}{ Tocopherols (mg/100 g dw) } \\
\hline$\alpha$-Tocopherol & $0.23 \pm 0.02$ & $3.37 \pm 0.01$ & $<0.001$ \\
\hline$\beta$-Tocopherol & nd & $0.22 \pm 0.04$ & - \\
\hline$\delta$-Tocopherol & $0.09 \pm 0.01$ & nd & - \\
\hline Sum & $0.33 \pm 0.03$ & $3.59 \pm 0.05$ & $<0.001$ \\
\hline
\end{tabular}

$\mathrm{dw}$ - dry weight basis; nd - not detected. C8:0 - Caprylic acid; C10:0 - Capric acid; C12:0 - Lauric acid; C14:0 - Myristic acid; C14:1 - Myristoleic acid; C15:0 - Pentadecanoic acid; C16:0 - Palmitic acid; C16:1 - Palmitoleic acid; C17:0 Heptadecanoic acid; C18:0 - Stearic acid; C18:1n9 - Oleic acid; C18:2n6 Linoleic acid; C18:3n3 - Linolenic acid; C20:0 - Arachidic acid; C20:2 - cis11,14 - Eicosadienoic acid; C20:3n3 - Eicosatrienoic acid; C22:0 - Behenic acid; C23:0 - Tricosanoic acid; C24:0 - Lignoceric acid. SFA - saturated fatty acids, MUFA - monounsaturated fatty acids, PUFA - polyunsaturated fatty acids.

determined in the stems, mainly due to the presence of $\alpha$-tocopherol (3.37 mg/100 g dw), with minor levels of $\beta$-tocopherol $(0.22 \mathrm{mg} / 100 \mathrm{~g}$ $\mathrm{dw})$. Significant lower concentrations of tocopherols were found in the fruits, also containing $\alpha$-tocopherol, but with $\delta$-tocopherol as the second vitamer ( 0.23 and $0.09 \mathrm{mg} / 100 \mathrm{~g} \mathrm{dw}$, respectively). To the authors' best knowledge, there are no previous studies of tocopherols composition in goji fruits and stems.

\subsection{Individual phenolic profile}

The peak characteristics (retention time, wavelength of maximum absorption and mass spectral data), tentative identification and quantification of phenolic compounds present in the hydromethanolic extracts of $L$. barbarum fruits and stems are presented in Table 3. An exemplificative phenolic profile of the hydromethanolic extracts of both types of samples, recorded at $280 \mathrm{~nm}$, is shown in Fig. 1. Fruits and stems presented different phenolic profile, with the presence of hydroxybenzoic (galloyl derivatives) and hydroxycinnamic (caffeic, $p$ coumaric, ferulic and sinapic acid derivatives) acid derivatives, flavan3-ols, and flavonols (quercetin and kaempferol derivatives). Sixteen compounds were identified in fruit samples: eight flavonols (peaks 6, $16,17,18,19,20,21$, and 22), seven phenolic acid derivatives (peaks $1,2,3,4,7,10$, and 14), and one flavan-3-ol (peak 9), while eleven compounds were detected in the stems, most of which were phenolic acid derivatives (peaks $2,4,5,7,8,11,12$, and 13), together with two flavonols (peaks 16 and 20) and one flavan-3-ol (peak 15). Only three chlorogenic acids (peaks 2, 4 and 7) were common to both samples. Peaks 7, 9, 12, 14, 16, 19, and 20 (5-O-caffeoylquinic acid, catechin, caffeic acid, $p$-coumaric acid, quercetin-3-O-rutinoside, quercetin-3-Oglucoside, and kaempferol-3-O-rutinoside, respectively) were identified by its UV and mass spectra, and retention characteristics in comparison with commercial standards. Compounds $\mathbf{1 9}$ and $\mathbf{2 0}$ had been previously reported by other authors in goji leaves (Mocan et al., 2017) and fruits (Bondia-Pons et al., 2014; Inbaraj et al., 2010).

Flavonols were the most abundant phenolic compounds in goji stems, although mostly due to the presence of quercetin-3-O-rutinose (rutin, peak 16), with minor levels of kaempferol-3-O-rutinose (peak 20). The presence of rutin as a major flavonol in different parts of goji plants has been consistently reported by several authors (Affes et al., 2017; Bondia-Pons et al., 2014; Mocan et al., 2017, 2015a,b, 2014; Protti et al., 2017; Qian et al., 2004; Zhang et al., 2016). Flavonols were less abundant in the fruits, despite they presented greater variety of these compounds. Quercetin-3-O-glucoside (isoquercitrin, peak 19) was positively identified by comparison with a standard. Peak 18 presented the same UV and mass spectral characteristics as compound 19 $\left([\mathrm{M}-\mathrm{H}]^{-}\right.$at $\left.m / z 463\right)$, thus corresponding to a quercetin hexoside, which was tentatively assigned as hyperoside (i.e., quercetin-3-O-galactoside), owing to the previous identification of both isoquercitrin and hyperoside in goji fruits (Lycium spp) by Qian et al. (2004) and Donno et al. (2015). This identity is also coherent with its chromatographic behaviour, as galactosides are expected to elute before its corresponding glucosides (Santos-Buelga et al., 2003). Peak 17 presented a pseudomolecular $[\mathrm{M}-\mathrm{H}]^{-}$at $m / z \quad 447$ releasing an $\mathrm{MS}^{2}$ fragment at $m / z 301$, allowing its identification as a quercetin-deoxyhexoside, tentatively associated to quercitrin (quercetin-3-O-rhamnoside) previously reported in different goji samples (Mocan et al., 2015a, 2014; Protti et al., 2017; Zhou et al., 2017). Peak 6 showed a UV spectra characteristic of a quercetin derivative, and a pseudomolecular ion $[\mathrm{M}-\mathrm{H}]^{-}$at $m / z$ 933, yielding fragments at $m / z 609\left([\mathrm{M}-\mathrm{H}-324]^{-}\right.$, loss of two hexosyl units) and $m / z 301$ ([M-H-308] $]^{-}$, loss of a rutinosyl unit), being tentatively identified as quercetin-dihexoside-rutinoside. A compound with the same characteristics (rutin di-hexose) was reported in hydromethanolic extracts of goji fruits from Finland (Bondia-Pons et al., 2014). Other two flavonols derived from kaempferol were also detected in the fruits. As above indicated, peak 21 was identified as kaempferol-3-O-glucoside by comparison with a standard, previously reported in goji fruits by Affes et al. (2017) and leaves by Mocan et al. (2017). Peak 22 was tentatively assigned as kaempferolrhamnoside based on its pseudomolecular ion $\left([\mathrm{M}-\mathrm{H}]^{-}\right.$at $\mathrm{m} / z$ 431) releasing a unique fragment at $m / z 285$, by analogy with the identifications made for quercetin glycosides.

Two flavan-3-ol derivatives were detected in the analysed samples and stems. Catechin (peak 9) was positively identified in the fruit by comparison with a commercial standard, whereas peak 15, found in the stems, was associated to a procyanidin dimer according to its UV spectrum, pseudomolecular ion $\left([\mathrm{M}-\mathrm{H}]^{-}\right.$at $\left.m / z 577\right)$ and $\mathrm{MS}^{2}$ fragments at $\mathrm{m} / \mathrm{z} 289,245$ and 203.

The remaining compounds detected in goji samples corresponded to phenolic acid derivatives, most of them derivatives of hydroxycinnamic acids, which were the most abundant compounds in the fruits. Three chlorogenic acids, peaks 2, 4 and 7 showing a pseudomolecular ion $[\mathrm{M}-\mathrm{H}]^{-}$at $m / z 353$ yielding a main product ion at $m / z 191$ (deprotonated quinic acid), were identified as cis and trans 3-O-caffeoylquinic acids and trans 5-O-caffeoylquinic acid, respectively, based on the hierarchical keys previously described by Clifford et al. (2003, 2005). These type of compounds are among the most common phenolic compounds usually reported in goji samples, although most authors do not indicate the particular derivative, but just refer to them as chlorogenic acid or isomers (Affes et al., 2017; Bondia-Pons et al., 2014; Donno et al., 2015; Mocan et al., 2015a,b, 2014; Qian et al., 2004; Zhang et al., 2016; Zhou et al., 2017). Only Mocan et al. (2017) described the presence of different caffeoylquinic acids in the leaves of cultivated $L$. barbarum from Romania, with particularly high contents of 3-O-caffeoylquinic acid. Inbaraj et al. (2010) also reported 3-O-caffeoylquinic 


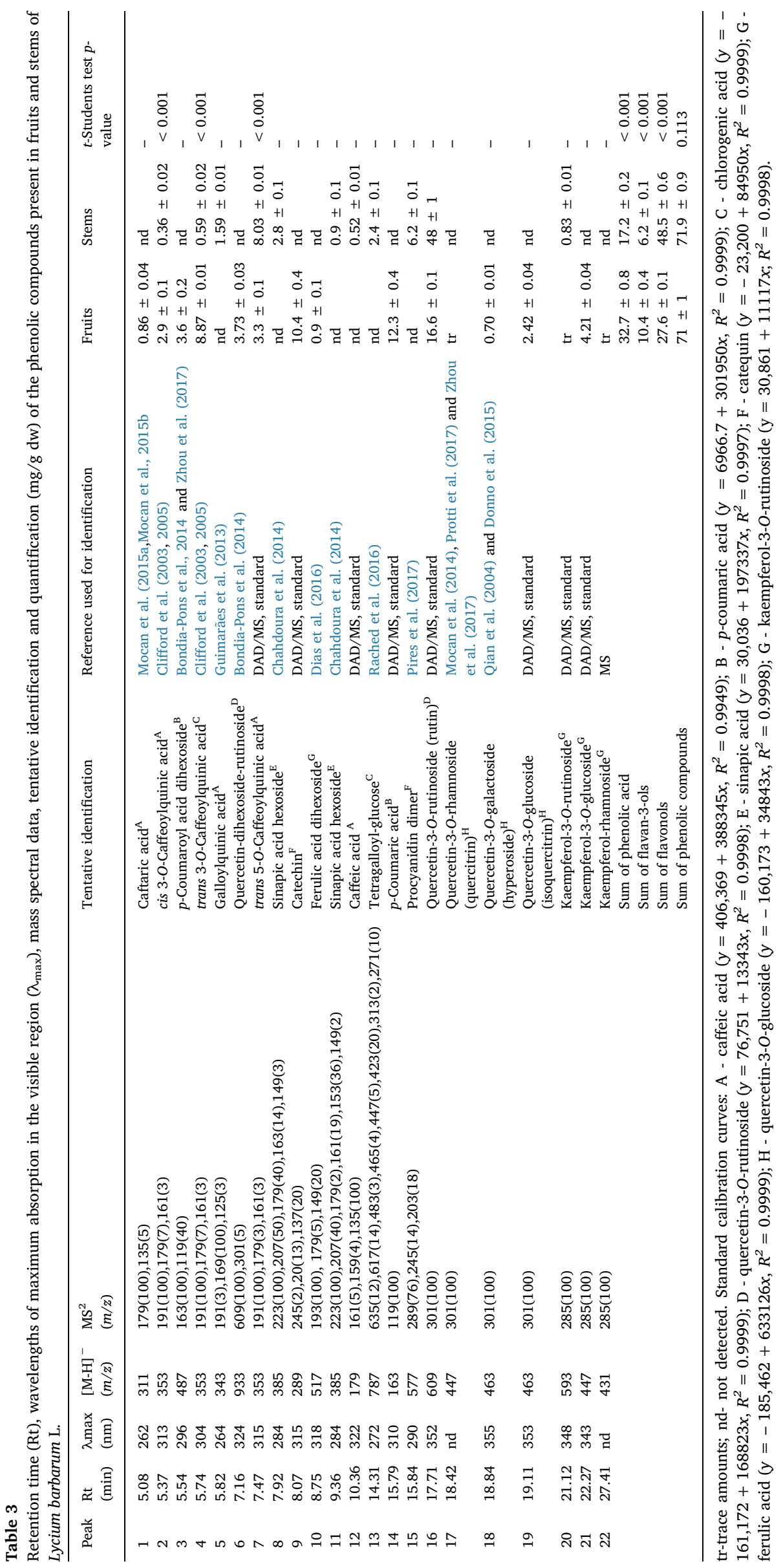




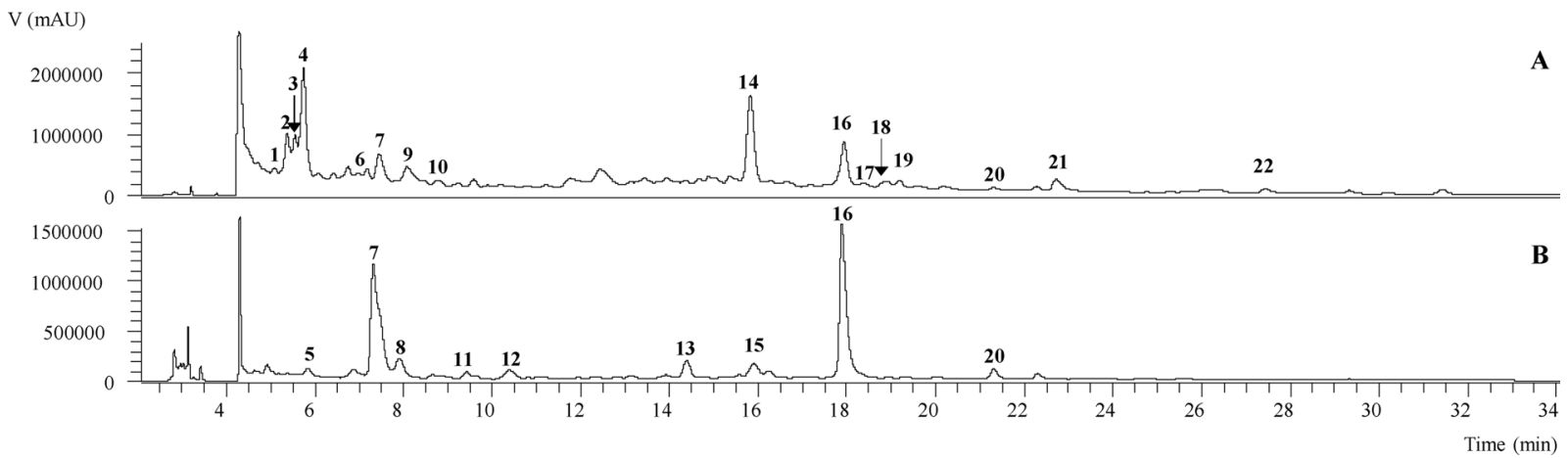

Fig. 1. HPLC phenolic profile recorded at $280 \mathrm{~nm}$ of the hydromethanolic extracts of fruits (A) and stems (B) of $L$. barbarum. Peak numbering is according to Table 3 .

Table 4

Antioxidant, hepatotoxic and antimicrobial activity of fruits and stems of Lycium barbarum L. (mean \pm SD).

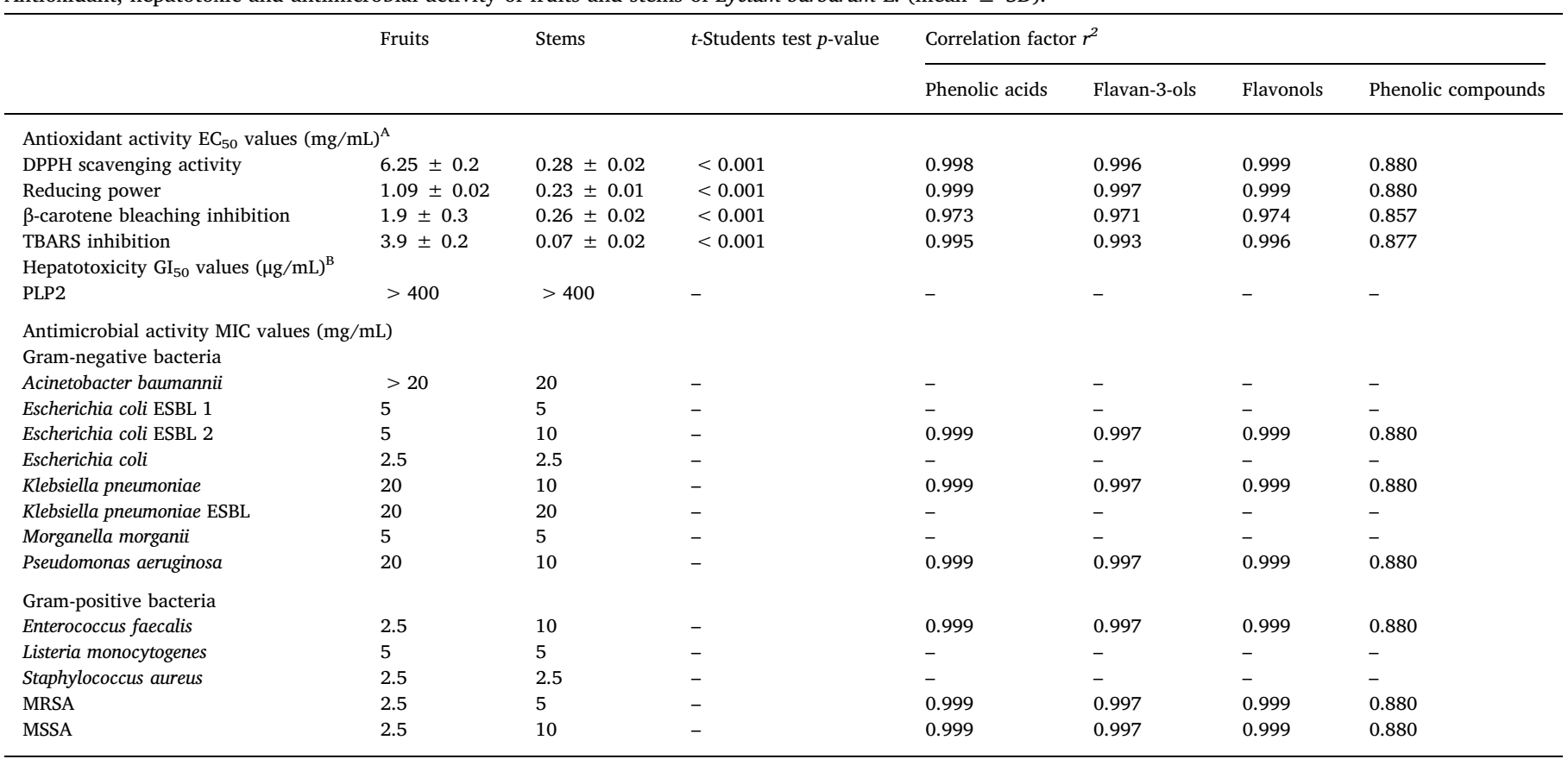

$\mathrm{EC}_{50}$ values correspond to the sample concentration achieving $50 \%$ of antioxidant activity or 0.5 of absorbance in reducing power assay. A- Trolox $\mathrm{EC}_{50}$ values: $43.03 \pm 1.71 \mu \mathrm{g} / \mathrm{mL}(\mathrm{DDPH}), 29.62 \pm 3.15 \mu \mathrm{g} / \mathrm{mL}$ (reducing power), $2.63 \pm 0.14 \mu \mathrm{g} / \mathrm{mL}$ ( $\beta$-carotene bleaching inhibition) and $3.73 \pm 1.9 \mu \mathrm{g} / \mathrm{mL}(\mathrm{TBARS}$ inhibition); B - Ellipticine $\mathrm{GI}_{50}$ values: $2.29 \mathrm{mg} / \mathrm{mL}$ (PLP2). MIC values correspond to the minimal extract concentration that inhibited the bacterial growth. ESBL extended spectrum $\beta$-lactamases. MRSA - Methicillin-resistant Staphylococcus aureus. MSSA - Methicillin-susceptible Staphylococcus aureus.

acid in the fruits of $L$. barbarum, although in lower amounts than the ones reported in this paper.

Peak 14, identified as p-coumaric acid by comparison with a standard, was the majority phenolic acid derivative in the fruits, whereas lower levels of caffeic acid (peak 12) were present in the stems. Other hydroxycinnamoyl derivatives detected in the samples were caftaric acid (peak 1), previously described in the leaves of $L$. barbarum (Mocan et al., 2015a,b), and different glycosides (peaks 3, 8, 10 and 11). Peak 3 presented a pseudomolecular ion $\left[\mathrm{M}-\mathrm{H}^{-}\right]^{-}$at $\mathrm{m} / \mathrm{z} 487$ releasing fragments at $m / z 163$ ( $-324 \mathrm{mu}$, loss of two hexosyl moieties) and 119, which is coherent with a p-coumaroyl acid dihexoside, as reported in goji fruits from Finland and Spain (Bondia-Pons et al., 2014); 6-O-transp-coumaroyl-2-O-glucopyranosyl-a-D-glucopyranoside was also recently identified by Zhou et al. (2017) in wolfberries from China. Similarly, peak 10, with a pseudomolecular ion $[\mathrm{M}-\mathrm{H}]^{-}$at $m / z 517$ and a main $\mathrm{MS}^{2}$ product ion at $\mathrm{m} / \mathrm{z} 193$ from the loss of $324 \mathrm{mu}$, could be tentatively identified as a ferulic acid dihexoside. Peaks $\mathbf{8}$ and $\mathbf{1 1}$ presented the same pseudomolecular ion $[\mathrm{M}-\mathrm{H}]^{-}$at $\mathrm{m} / z 385$ and an $\mathrm{MS}^{2}$ fragment at $m / z 223$ (sinapic acid aglycone), corresponding to the loss of an hexosyl unit, so that they were tentatively identified as sinapic acid hexosides.

Finally, peaks $\mathbf{5}$ and $\mathbf{1 3}$ were associated to galloyl derivatives. The first one was identified as galloylquinic acid based on its pseudomolecular ion $\left([\mathrm{M}-\mathrm{H}]^{-}\right.$at $m / z$ 343) and the major $\mathrm{MS}^{2}$ fragment at $\mathrm{m} / \mathrm{z}$ 169 [gallic acid-H] $^{-}$, from the loss of quinic acid moiety $(-152 \mathrm{mu})$. Peak 13 was assigned as tetragalloyl-glucose from its pseudomolecular ion $[\mathrm{M}-\mathrm{H}]^{-}$at $m / z 787$ and fragment ions at $m / z 635,483$, and 313 from the consecutive loss of three gallic acid units. The identification of both compounds was supported by its comparison with previously obtained data available in a compound library (Guimarães et al., 2013; Rached et al., 2016). To the authors' best knowledge, these compounds have not been previously cited in goji samples.

The total content of phenolic compounds did not show any statistically significant difference between fruits and stems of goji samples. However, significant differences were found between samples when considering each family of phenolic compounds, being phenolic acid derivatives the majority compounds in the fruits $(32.7 \mathrm{mg} / \mathrm{g} v \mathrm{~s}$ $17.2 \mathrm{mg} / \mathrm{g}$ in the stems) and flavonols in the stems $(48.5 \mathrm{mg} / \mathrm{g} v \mathrm{~s}$ 


\section{$27.6 \mathrm{mg} / \mathrm{g}$ in the fruits).}

Quercetin-3-O-rutinoside was by far the major phenolic compound in stems $(48 \mathrm{mg} / \mathrm{g}$ extract) and fruits $(16.6 \mathrm{mg} / \mathrm{g}$ extract), followed in these latter by $p$-coumaric acid $(12.3 \mathrm{mg} / \mathrm{g}$ extract). The differences between fruits and stems are explained by the clear difference in plant tissues. Although a greater amount of flavonols might be expected in the fruits, the obtained results could be explained by the edafoclimatic characteristics, degree of ripening and storage conditions (Haminiuk et al., 2012).

\subsection{Bioactivities of fruit and stem hydromethanolic extracts}

Data regarding the antioxidant, hepatotoxic and antibacterial activities are presented in Table 4. The hydromethanolic extracts of $L$. barbarum stems showed the highest antioxidant activity in all assays: DPPH scavenging activity, reducing power, $\beta$-carotene bleaching inhibition and TBARS inhibition $\left(\mathrm{EC}_{50}=0.28,0.23,0.26\right.$, and $0.07 \mathrm{mg}$ / $\mathrm{mL}$, respectively). Similar results were reported by Liu et al. (2017) in ethanolic extracts of L. barbarum stems from Taiwan, namely DPPH scavenging activity and reducing power $(0.102$ and $0.167 \mathrm{mg} / \mathrm{mL}$, respectively). On the other hand, Jabbar et al. (2014) reported lower EC $_{50}$ values in methanolic extracts of goji fruits from China, regarding DPPH scavenging activity and reducing power $(0.042$ and $0.121 \mathrm{mg} / \mathrm{mL}$, respectively), in comparison with the herein analysed hydromethanolic extract.

The antioxidant activity revealed by the herein study samples could be due to their high content in phenolic acids derivatives and flavonoids. The antioxidant activity of phenolic acid derivatives depends on the number of hydroxyl groups in the molecule, that would be strengthened by steric hindrance. Moreover, the electron-withdrawing properties of the carboxylate group in benzoic acids has a negative influence on the H-donating abilities of the hydroxy benzoates, being hydroxylated cinnamates more effective than benzoate counterpart (Rice-Evans et al., 1996). The presence of multiple hydroxyl groups in flavonoids and other phenolics structures gives them a reducing character. In fact, it has been shown in in vitro assays that many of these compounds possess a strong antioxidant activity. This activity is particularly high, three to four fold higher in ortho-dihydroxy flavonoids (those containing a catechol group in their aromatic rings) such as flavonols or flavanol (Vicente and Boscaiu, 2018). Thus, the differences in the phenolic compounds family present in each of the study plant part (phenolic acids for fruits and flavonols in stems), could explain the greater antioxidant capacity of the stems.

Neither fruits nor stems revealed toxicity towards a porcine liver primary culture (PLP2).

Regarding antibacterial activity (Table 4), both samples showed better results against Gram-positive than against Gram-negative bacteria, with MIC values ranging between 2.5 and $10 \mathrm{mg} / \mathrm{mL}$. The lowest MIC values were determined for $E$. faecalis $(2.5 \mathrm{mg} / \mathrm{mL})$, L. monocytogenes $(5 \mathrm{mg} / \mathrm{mL}), S$. aureus $(2.5 \mathrm{mg} / \mathrm{mL})$, MRSA $(2.5 \mathrm{mg} / \mathrm{mL})$, and MSSA $(2.5 \mathrm{mg} / \mathrm{mL})$. As for Gram-negative bacteria, the stems presented higher activity against $A$. baumannii $(20 \mathrm{mg} / \mathrm{mL}), K$. pneumonia $(10 \mathrm{mg} /$ $\mathrm{mL}$ ), and $P$. aeruginosa $(10 \mathrm{mg} / \mathrm{mL})$. Mocan et al. (2017) and Mocan et al. (2015b) reported lower MIC values in goji leaves and flowers, respectively, against both Gram-negative and positive bacteria. A possible explanation could be that the bacteria used by those authors were ATCC (with no resistance profile), so that lower concentrations of extracts could be needed to inhibit the growth of the bacterial strains.

As it can also be seen in Table 4 good correlations were obtained between the different families of analysed phenolic compounds and the antioxidant activity $\left(r^{2}<0.8\right)$. Regarding antibacterial assays, good correlation coefficients were observed for Escherichia coli ESBL 2, Klebsiella pneumonia, Pseudomonas aeruginosa, and Enterococcus faecalis.

The presence of phenolic compounds, namely flavonoids and phenolic acids (e.g. chlorogenic acids derivatives) could be related to the antibacterial potential of the study samples. Flavonoids are known to be synthesized by plants in response to microbial infection, thus explaining the in vitro antimicrobial activity of these substances against a wide array of microorganisms. Their activity is probably due to their ability to complex with extracellular and soluble proteins, which may disrupt the microbial membrane (Cushnie and Lamb, 2005; Kabir et al., 2014). The antimicrobial activity of polyphenols has also been attributed to their structural features, as well as $\mathrm{pH}$ and sodium chloride concentration, resulting in physiological changes in the microorganisms and eventual cell death (Kabir et al., 2014). Chlorogenic acid is a phenolic ester of caffeic acid and (-)-quinic acid (Chiang et al., 2004), which is metabolized into active compounds, such as quinic, caffeic, benzoic, hippuric, ferulic, isoferulic, and hydroxybenzoic acids. Studies carried out by Kabir et al. (2014) confirm that chlorogenic acids and related compounds exhibited a potent antimicrobial activity, and a synergistic effect between compounds. Thus, these compounds could be related to the antimicrobial potential revealed in these plant parts.

Overall, the stems of $L$. barbarum showed higher values of energy, fat, proteins and ash, as also monounsaturated fatty acids, tocopherols, and flavonols (i.e., quercetin-3-O-rutinoside). They also presented greater antioxidant capacity and higher activity against Gram-negative bacteria. The fruits of $L$. barbarum possessed higher contents of sugars (mainly fructose and glucose), as expected, polyunsaturated fatty acids, hydroxycinnamoyl derivatives ( $p$-coumaric acid and chlorogenic acid derivatives), and flavan-3-ols (catechin); they also showed higher activity against Gram-positive bacteria.

All in all, this study allowed verifying that not only the fruit but also goji stems can be sources of compounds with interesting nutritional and bioactive properties and, therefore, they could be useful for nutraceutical formulations or its incorporation into foods with functional properties. Since stems are by-products, besides its possible beneficial effects to consumers, they also provide industrial sustainability and could be used as an add value by-product scarcely noticed up to now.

\section{Acknowledgements}

The authors are grateful to the Foundation for Science and Technology (FCT, Portugal) and FEDER under Programme PT2020 for financial support to CIMO (UID/AGR/00690/2013), T.C.S.P. Pires (SFRH/BD/129551/2017) grant and L. Barros contract. The GIP-USAL is financially supported by the Spanish Government through the project AGL2015-64522-C2-2-R. The authors are grateful to FEDER-Interreg España-Portugal programme for financial support through the project 0377_Iberphenol_6_E.

\section{Appendix A. Supplementary data}

Supplementary material related to this article can be found, in the online version, at doi:https://doi.org/10.1016/j.indcrop.2018.06.046.

\section{References}

Abreu, R.M.V., Ferreira, I.C.F.R., Calhelha, R.C., Lima, R.T., Vasconcelos, M.H., Adega, F., Chaves, R., Queiroz, M.J.R.P., 2011. Anti-hepatocellular carcinoma activity using human HepG2 cells and hepatotoxicity of 6-substituted methyl 3-aminothieno[3,2-b] pyridine-2- carboxylate derivatives: in vitro evaluation, cell cycle analysis and QSAR studies. Eur. J. Med. Chem. 46, 5800-5806. http://dx.doi.org/10.1016/j.ejmech. 2011.09.029.

Affes, M., Fakhfakh, J., Daoud, I., Brieudes, V., Halabalaki, M., El Feki, A., Allouche, N., 2017. UHPLC/HR-ESI-MS/MS profiling of phenolics from Tunisian Lycium arabicum Boiss. Antioxidant and anti-lipase activities' evaluation. Chem. Biodivers. 14.

Amagase, H., Farnsworth, N.R., 2011. A review of botanical characteristics, phytochemistry, clinical relevance in efficacy and safety of Lycium barbarum fruit (Goji). Food Res. Int.

AOAC, 2016. Official Methods of Analysis of AOAC International. The Association of Official Analytical Chemists International.

Barros, L., Pereira, E., Calhelha, R.C., Dueñas, M., Carvalho, A.M., Santos-Buelga, C., Ferreira, I.C.F.R., 2013. Bioactivity and chemical characterization in hydrophilic and lipophilic compounds of Chenopodium ambrosioides L. J. Funct. Foods 5, 1732-1740.

Bessada, S.M.F., Barreira, J.C.M., Barros, L., Ferreira, I.C.F.R., Oliveira, M.B.P.P., 2016. Phenolic profile and antioxidant activity of Coleostephus myconis (L.) Rchb.f.: An 
underexploited and highly disseminated species. Ind. Crops Prod. 89, 45-51.

Bondia-Pons, I., Savolainen, O., Törrönen, R., Martinez, J.A., Poutanen, K., Hanhineva, K., 2014. Metabolic profiling of Goji berry extracts for discrimination of geographical origin by non-targeted liquid chromatography coupled to quadrupole time-of-flight mass spectrometry. Food Res. Int. 63, 132-138.

Chahdoura, H., Barreira, J.C.M., Barros, L., Santos-Buelga, C., Ferreira, I.C.F.R., Achour, L., 2014. Phytochemical characterization and antioxidant activity of Opuntia microdasys (Lehm.) Pfeiff flowers in different stages of maturity. J. Funct. Foods 9, 27-37.

Chiang, Y.-M. Chuang, D.-Y., Wang, S.-Y., Kuo, Y.-H., Tsai, P.-W., Shyur, L.-F., 2004. Metabolite profiling and chemopreventive bioactivity of plant extracts from Bidens pilosa. J. Ethnopharmacol. 95, 409-419.

Clifford, M.N., Johnston, K.L., Knight, S., Kuhnert, N., 2003. Hierarchical scheme for LCMSn identification of chlorogenic acids. J. Agric. Food Chem. 51, 2900-2911.

Clifford, M.N., Knight, S., Kuhnert, N., 2005. Discriminating between the six isomers of dicaffeoylquinic acid by LC-MSn. J. Agric. Food Chem. 53, 3821-3832.

Cushnie, T.P.T., Lamb, A.J., 2005. Antimicrobial activity of flavonoids. Int. J. Antimicrob. Agents 26, 343-356.

D'Amato, A., Esteve, C., Fasoli, E., Citterio, A., Righetti, P.G., 2013. Proteomic analysis of Lycium barbarum (Goji) fruit via combinatorial peptide ligand libraries. Electrophoresis 34, 1729-1736.

Dahech, I., Farah, W., Trigui, M., Hssouna, A.Ben, Belghith, H., Belghith, K.S., Abdallah, F.Ben, 2013. Antioxidant and antimicrobial activities of Lycium shawii fruits extract. Int. J. Biol. Macromol. 60, 328-333.

Dias, M.I., Barros, L., Morales, P., Sánchez-Mata, M.C., Oliveira, M.B.P.P., Ferreira, I.C.F., 2015. Nutritional parameters of infusions and decoctions obtained from Fragaria vesca L. roots and vegetative parts. LWT - Food Sci. Technol. 62, 32-38.

Dias, M.I., Barros, L., Morales, P., Cámara, M., Alves, M.J., Oliveira, M.B.P.P., SantosBuelga, C., Ferreira, I.C.F.R., 2016. Wild Fragaria vesca L. fruits: a rich source of bioactive phytochemicals. Food Funct. 7, 4523-4532.

Dong, J.Z., Lu, D.Y., Wang, Y., 2009. Analysis of flavonoids from leaves of cultivated Lycium barbarum L. Plant Foods Hum. Nutr. 64, 199-204.

Donno, D., Beccaro, G.L., Mellano, M.G., Cerutti, A.K., Bounous, G., 2015. Goji berry fruit (Lycium spp.): antioxidant compound fingerprint and bioactivity evaluation. J. Funct. Foods 18, 1070-1085.

Guimarães, R., Barros, L., Dueñas, M., Carvalho, A.M., Queiroz, M.J.R.P., Santos-Buelga, C., Ferreira, I.C.F.R., 2013. Characterisation of phenolic compounds in wild fruits from northeastern Portugal. Food Chem. 141, 3721-3730.

Haminiuk, C.W.I., Maciel, G.M., Plata-Oviedo, M.S.V., Peralta, R.M., 2012. Phenolic compounds in fruits - an overview. Int. J. Food Sci. Technol. 47, 2023-2044.

Inbaraj, B.S., Lu, H., Kao, T.H., Chen, B.H., 2010. Simultaneous determination of phenolic acids and flavonoids in Lycium barbarum Linnaeus by HPLC-DAD-ESI-MS. J. Pharm. Biomed. Anal. 51, 549-556.

Jabbar, S., Abid, M., Zeng, X., 2014. Nutritional, phytochemical characterization and antioxidant capacity of Ningxia Wolfberry (Lycium barbarum L.). J. Chem. Soc. Pak. 36, 1079.

Kabir, F., Katayama, S., Tanji, N., Nakamura, S., 2014. Antimicrobial effects of chlorogenic acid and related compounds. J. Korean Soc. Appl. Biol. Chem. 57, 359-365.

Kuete, V., Ango, P.Y., Fotso, G.W., Kapche, G.D.W.F., Dzoyem, J.P., Wouking, A.G., Ngadjui, B.T., Abegaz, B.M., 2011a. Antimicrobial activities of the methanol extract and compounds from Artocarpus communis (Moraceae). BMC Complement. Altern. Med. 11, 42.

Kuete, V., Justin, K., Louis, P.S., Bathelemy, N., Herve, M.P.P., Pantaleon, A., Bonaventure, T.N., 2011b. Antimicrobial activities of the methanol extract, fractions and compounds from Ficus polita Vahl. (Moraceae). BMC Complement. Altern. Med. 11,6 .

Liu, H., Fan, Y., Wang, W., Liu, N., Zhang, H., Zhu, Z., Liu, A., 2012. Polysaccharides from Lycium barbarum leaves: isolation, characterization and splenocyte proliferation activity. Int. J. Biol. Macromol. 51, 417-422

Liu, S.C., Lin, J.T., Hu, C.C., Shen, B.Y., Chen, T.Y., Chang, Y.L., Shih, C.H., Yang, D.J., 2017. Phenolic compositions and antioxidant attributes of leaves and stems from three inbred varieties of Lycium chinense Miller harvested at various times. Food Chem. 215, 284-291.

Mikulic-Petkovsek, M., Schmitzer, V., Slatnar, A., Stampar, F., Veberic, R., 2012. Composition of sugars, organic acids, and total phenolics in 25 wild or cultivated berry species. J. Food Sci. 77, 1064-1071.

Mocan, A., Vlase, L., Vodnar, D.C., Bischin, C., Hanganu, D., Gheldiu, A.-M., Oprean, R., Silaghi-Dumitrescu, R., Crișan, G., 2014. Polyphenolic content, antioxidant and antimicrobial activities of Lycium barbarum L. and Lycium chinense Mill. leaves. Molecules 19, 1511-1516.

Mocan, A., Vlase, L., Raita, O., Hanganu, D., Păltinean, R., Dezsi, S., Gheldiu, A.M., Oprean, R., Crişan, G., 2015a. Comparative studies on antioxidant activity and polyphenolic content of Lycium barbarum L. and Lycium chinense Mill. leaves. Pak. J. Pharm. Sci. 28, 1511-1515.

Mocan, A., Vlase, L., Vodnar, D.C., Gheldiu, A.M., Oprean, R., Crisan, G., 2015b. Antioxidant, antimicrobial effects and phenolic profile of Lycium barbarum L. flowers. Molecules 20, 15060-15071A.

Mocan, A., Zengin, G., Simirgiotis, M., Schafberg, M., Mollica, A., Vodnar, D.C., Crișan, G., Rohn, S., 2017. Functional constituents of wild and cultivated Goji (L. barbarum L.) leaves: phytochemical characterization, biological profile, and computational studies. J. Enzyme Inhib. Med. Chem. 32, 153-168.

Pires, T.C.S.P., Dias, M.I., Barros, L., Ferreira, I.C.F.R., 2017. Nutritional and chemical characterization of edible petals and corresponding infusions: valorization as new food ingredients. Food Chem. 220, 337-343.

Potterat, O., Food, N., 2010. Goji (Lycium barbarum and L. Chinense): Phytochemistry, Pharmacology and Safety in the Perspective of Traditional Uses and Recent Popularity. pp. 7-19.

Protti, M., Gualandi, I., Mandrioli, R., Zappoli, S., Tonelli, D., Mercolini, L., 2017. Analytical profiling of selected antioxidants and total antioxidant capacity of goji (Lycium spp.) berries. J. Pharm. Biomed. Anal. 143, 252-260.

Qian, J.Y., Liu, D., Huang, A.G., 2004. The efficiency of flavonoids in polar extracts of Lycium chinense Mill fruits as free radical scavenger. Food Chem. 87, 283-288.

Rached, I., Barros, L., Fernandes, I.P., Santos-Buelga, C., Rodrigues, A.E., Ferchichi, A., Barreiro, M.F., Ferreira, I.C.F.R., 2016. Ceratonia siliqua L. hydroethanolic extract obtained by ultrasonication: antioxidant activity, phenolic compounds profile and effects in yogurts functionalized with their free and microencapsulated forms. Food Funct. 7, 1319-1328.

Rice-Evans, C.A., Miller, N.J., Paganga, G., 1996. Structure-antioxidant activity relationships of flavonoids and phenolic acids. Free Radic. Biol. Med. 20, 933-956.

Santos-Buelga, C., Williamson, G., Royal Society of Chemistry (Great Britain), 2003. Methods in Polyphenol Analysis. Royal Society of Chemistry.

Tang, W.M., Chan, E., Kwok, C.Y., Lee, Y.K., Wu, J.H., Wan, C.W., Chan, R.Y.K., Yu, P.H.F., Chan, S.W., 2012. A review of the anticancer and immunomodulatory effects of Lycium barbarum fruit. Inflammopharmacology 20, 307-314.

Vicente, O., Boscaiu, M., 2018. Flavonoids: antioxidant compounds for plant defence... and for a healthy human diet. Not. Bot. Horti Agrobot. Cluj-Napoca 46, 14-21.

Yan, Y., Ran, L., Cao, Y., Qin, K., Zhang, X., Luo, Q., 2014. Nutritional, phytochemical characterization and antioxidant capacity of Ningxia Wolfberry (Lycium barbarum L.). J. Chem. Soc. Pak. 36, 1079-1087.

Zhang, Q., Chen, W., Zhao, J., Xi, W., 2016. Functional constituents and antioxidant activities of eight Chinese native goji genotypes. Food Chem. 200, 230-236.

Zhou, Z.Q., Xiao, J., Fan, H.X., Yu, Y., He, R.R., Feng, X.L., Kurihara, H., So, K.F., Yao, X.S., Gao, H., 2017. Polyphenols from wolfberry and their bioactivities. Food Chem. 214, 644-654. 